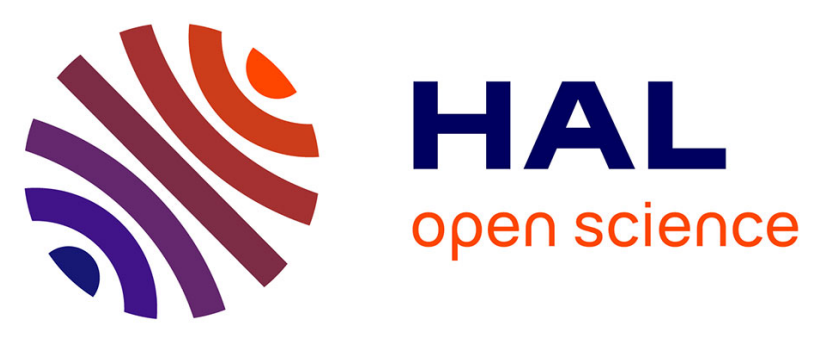

\title{
Quantitative kinetic modeling in photoresponsive supramolecular chemistry: the case of water-soluble azobenzene/cyclodextrin complexes
}

Jorge Royes, Camille Courtine, Corinne Lorenzo, Nancy Lauth-de Viguerie, Anne-Françoise Mingotaud, Véronique Pimienta

\section{To cite this version:}

Jorge Royes, Camille Courtine, Corinne Lorenzo, Nancy Lauth-de Viguerie, Anne-Françoise Mingotaud, et al.. Quantitative kinetic modeling in photoresponsive supramolecular chemistry: the case of water-soluble azobenzene/cyclodextrin complexes. Journal of Organic Chemistry, 2020, 85 (10), pp.6509-6518. 10.1021/acs.joc.0c00461 . hal-02559449

\author{
HAL Id: hal-02559449 \\ https://hal.science/hal-02559449
}

Submitted on 9 Nov 2020

HAL is a multi-disciplinary open access archive for the deposit and dissemination of scientific research documents, whether they are published or not. The documents may come from teaching and research institutions in France or abroad, or from public or private research centers.
L'archive ouverte pluridisciplinaire HAL, est destinée au dépôt et à la diffusion de documents scientifiques de niveau recherche, publiés ou non, émanant des établissements d'enseignement et de recherche français ou étrangers, des laboratoires publics ou privés. 


\section{Quantitative kinetic modeling in photoresponsive}

\section{supramolecular chemistry: the case of water-soluble azobenzene/cyclodextrin complexes}

Jorge Royes $^{a, b}{ }^{\ddagger}$, Camille Courtine $^{a}$, Corinne Lorenzo ${ }^{b}$, Nancy Lauth de Viguerie ${ }^{a}$, AnneFrançoise Mingotaud ${ }^{a, *}$, Véronique Pimienta $^{a, *}$

${ }^{a}$ Laboratoire des IMRCP, Université de Toulouse, CNRS UMR 5623, Université Toulouse III Paul Sabatier, 118 Rte de Narbonne, F-31062 Toulouse cedex, France

b ITAV, Université de Toulouse, CNRS, UPS, 1 place Pierre Potier 31106 Toulouse Cedex 1, France

${ }^{\ddagger}$ present address: PASTEUR, Département de Chimie, École Normale Supérieure, PSL University, Sorbonne Université, CNRS UMR 8640, 24 rue Lhomond, 75005 Paris France.

KEYWORDS (Word Style "BG_Keywords"). Host-guest, supramolecular, photochemistry, azobenzene, cyclodextrin, modeling 


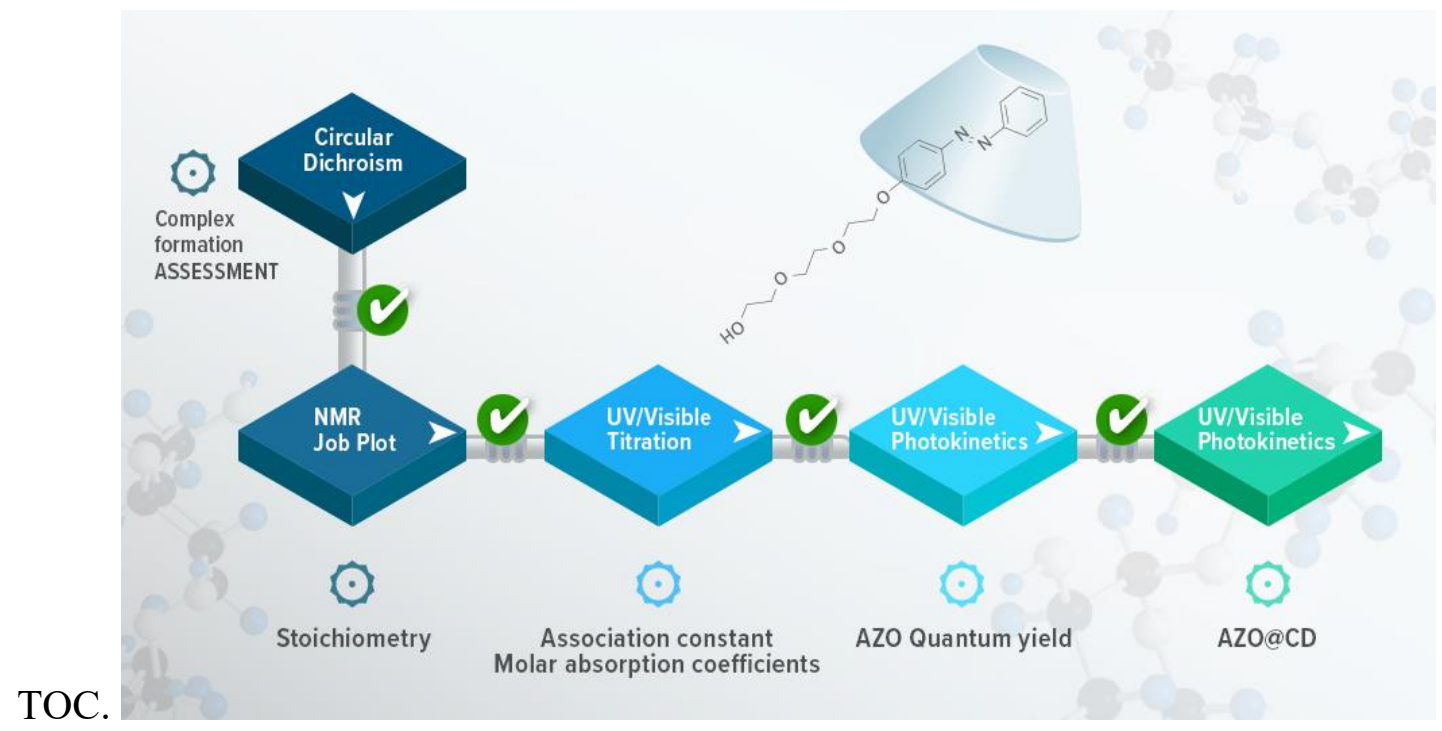

ABSTRACT (Word Style "BD_Abstract"). Hydrophilic host-guest complexes, consisting in a water-soluble azobenzene and $\alpha-, \beta$ - or $\gamma$-cyclodextrins, have been proposed as a model to study supramolecular photoresponsive systems in aqueous environments through a full spectrometric approach combined to a simulation and data fitted methodology. Various essential and complementary spectroscopic techniques were used: circular dichroism to determine whether the complex was formed or not, NMR for the stoichiometry elucidation and UV-visible spectrophotometry to obtain the association equilibrium constant of each complex and the quantum yield for each photochemical process. A step by step fitting procedure is presented, which enables the determination of all thermodynamic and photokinetic parameters. The sequential methodology is applied in order to dissipate all uncertainties on the variability of the results and to develop a relevant and reliable protocol applicable to other types of complexes. The proposed procedure has thus been shown to be very robust and largely applicable to other photoresponsive host-guest systems. 


\section{INTRODUCTION}

Based on all recognition phenomena present in nature, host-guest interactions have been motivating the chemists' research for a long time, starting back in the 60s, with the early work of Cram, Pedersen and Lehn and their Nobel Prize in 1987. Beside the synthesis of molecules with programmed host-guest interactions, an essential part of supramolecular chemistry involves the characterization of the produced complexes. For basic A/B complexes, two central parameters are sought, namely the stoichiometry of the complex and its association constant. To determine these parameters, linearization and graphical determination have long been used, especially the continuous variation plots (so called Job's plot) for the stoichiometry determination and BenesiHildebrand linearization for the association constant ${ }^{1}$.

Cycodextrins (CD) are among the most popular supramolecular hosts ${ }^{2}$. Their high solubility in water together with their central hydrophobic cavity make them interesting supramolecular hosts. Various hydrophobic guests with different affinity to the CD inner pocket have thus been described, ranging from adamantane to different aromatic molecules such as phenyl, naphthalene or ferrocenyl moieties.

The interaction of photoreactive guests with $\mathrm{CD}$ may give rise to inclusion complexes, whose formation and dissociation can be reversibly controlled through irradiation. For instance, azobenzene derivatives-CD photoresponsive inclusion complexes have been known for more than 30 years $^{3}$. From this time on, they have become a powerful building block to prepare advanced materials with photomodulable properties. Indeed, the excellent biocompatibility of azobenzenes@CD inclusion complexes makes them good photo-switches in the emerging field of 
biointerfaces, or materials in contact with biological samples ${ }^{4}$. For example, self-healing materials ${ }^{5}$, artificial muscles ${ }^{6}$, biomaterials with photomodulable mechanical properties ${ }^{7}$ or drug controlled release materials ${ }^{8}$ have been described in the recent years.

Despite the numerous examples of azobenzene@CD complexes applications, there are only a few quantitative studies about their photoisomerization mechanism. A couple of early works characterized the photochemical ${ }^{9}$ and thermal relaxation constants ${ }^{10}$ of azobenzene@CD complexes in different solvents. Later, Liu et al. studied the binding models and relative affinity of azobenzene tethered cyclodextrins $v s$ different aliphatic alcohol guests ${ }^{11}$. It is worth mentioning that all these studies were carried out in organic solvents or aqueous mixtures of them due to the low solubility of azobenzene compounds in water. This poor water solubility of azobenzenes@CD supramolecular photoswitches is a strong limitation for biological applications. Different strategies to increase the water solubility of the azobenzene@CD photoswitches have included grafting on hydrophilic moieties, such as polyethyleneglycol ${ }^{12}$, polyacrylate ${ }^{5,13}$, polysaccharides ${ }^{7 b}$ or peptides ${ }^{14}$, or introducing charged moieties ${ }^{15}$ such as ammonium ${ }^{10,16}$ or carboxylates ${ }^{17}$. All these studies are however limited to the determination of the stoichiometry and affinity constant of the complex formed by hydrophilic azobenzene derivatives as guests. Thus, there is a strong lack of thorough characterization of the isomerization kinetics and related quantum yields for azobenzene@CD complexes in water.

The purpose of this study was to fully characterize the complexation, kinetic and spectral properties of a water soluble azobenzene compound (noted AZO) in presence of $\alpha-, \beta-$ and $\gamma \mathrm{CD}$. A quantitative approach of the photoisomerization processes in the presence of $\mathrm{CD}$ was obtained by simulation and data fitting, following a step by step procedure described in scheme 1 . We first determined the stoichiometry and equilibrium complexation constants of the AZO compound in the 
presence of the three CDs. Once these parameters were determined, we analyzed the photoisomerization of free AZO in solution to finally reach a full mechanism involving the photokinetics of the inclusion complexes. We will give a detailed description of the fitting procedure in order to get a transparent and pedagogical description of the methodology followed. Thanks to this procedure, we kept a minimum number of parameters to be fitted at each step allowing a reliable determination of the extracted parameters which were, once determined, fixed in the following step. The step-by-step approach developed in this work is applicable to any other photoresponsive supramolecular complexes.

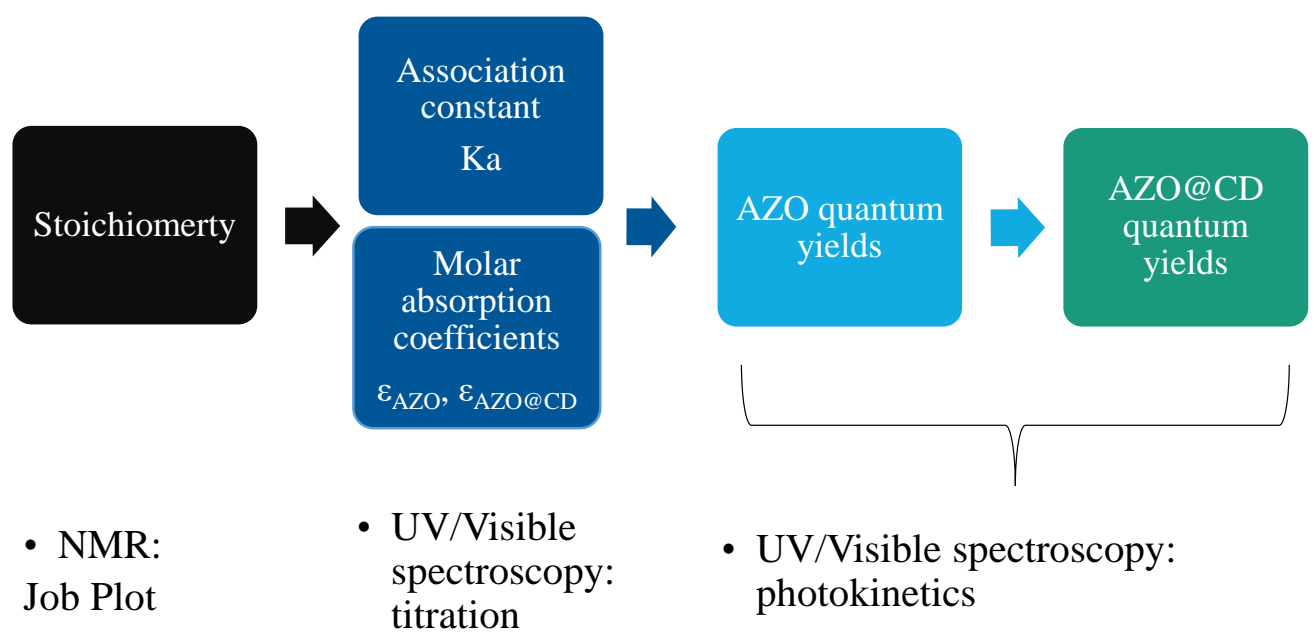

Scheme 1. Step by step procedure principle used to characterize AZO@CD complexes.

\section{RESULTS AND DISCUSSION}

A monosubstituted azobenzene containing a tri(ethyleneoxide) moiety in 4-position (AZO) was synthesized following already described procedures $^{7 \mathrm{a}}$ (Chart 1). The reported complexation between ethyleneoxide oligomers and $\alpha$-cyclodextrin was prevented by limiting the length of this 
chain to three units ${ }^{13}$. Nevertheless, even with this short hydrophilic unit, AZO could be solubilized in water at concentrations up to $10^{-4} \mathrm{M}$. NMR confirmed that the synthesized compound is the trans isomer, $\mathrm{AZO}$.

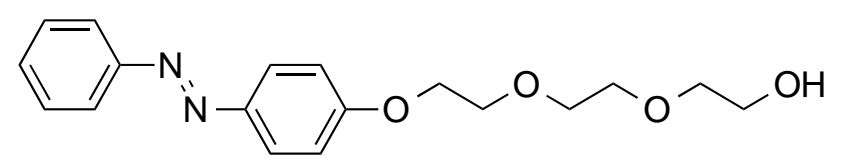

Chart 1. Molecular structure of synthesized AZO chromophore.

\section{I - Inclusion complexes}

Different spectroscopic techniques such as NMR, UV-visible absorption, or circular dichroism have traditionally been used to demonstrate supramolecular complexation. We have used three complementary techniques: circular dichroism to determine whether the complex was formed or not, NMR for the stoichiometry elucidation and UV-visible spectrophotometry ${ }^{18}$ to obtain the association equilibrium constant and the spectra of the supramolecular complexes.

The circular dichroism spectra of isolated AZO $t$ and $\alpha-, \beta$ - and $\gamma \mathrm{CD}$ were silent (Figure S1) while a positive and a negative Cotton effect centered on $\pi-\pi^{*}(\sim 350 \mathrm{~nm})$ and $\mathrm{n}-\pi^{*}(\sim 450 \mathrm{~nm})$ AZO $t$ absorption bands, respectively, were detected in aqueous solutions containing $\mathrm{AZO} t$ and $\alpha$ - $\beta$ - or $\gamma \mathrm{CD}$ (Figure 1a). The observed signals prove the chirality transfer from $\mathrm{CD}$ to $\mathrm{AZO} t$ and the complexation of $\mathrm{AZO} t$ with $\mathrm{CD}$ in water. The position of the circular dichroism bands $\left(\lambda_{\max }\right)$ of the three compounds agree with the UV-visible absorption spectra. This $\lambda_{\max }$ appears at the same value as for free AZOt $(346 \mathrm{~nm}$ ) and AZOt@ $@ \gamma \mathrm{CD}$, while it is shifted to 337 and $354 \mathrm{~nm}$ for respectively $\beta$ - and $\alpha \mathrm{CD}$ complexes. The sign of Cotton effects indicates the relative orientation of the guest 
into the CD axis ${ }^{11}$. Positive Cotton effect of $\pi-\pi^{*}$ band and negative Cotton effect of $n-\pi^{*}$ band indicated the formation of an inclusion complex, where the long axis of AZO molecules was inserted parallel to $\mathrm{CD}$ axis. In addition, at constant $\mathrm{AZO} t$ and $\mathrm{CD}$ concentration, the intensity of circular dichroism signal was higher for $\alpha \mathrm{CD}>\beta \mathrm{CD}>\gamma \mathrm{CD}$ (Figure 1a). These results suggest that $\alpha \mathrm{CD}$ is able to establish more effective supramolecular interactions with $\mathrm{AZO} t$ than $\beta \mathrm{CD}$ and $\gamma \mathrm{CD}$.
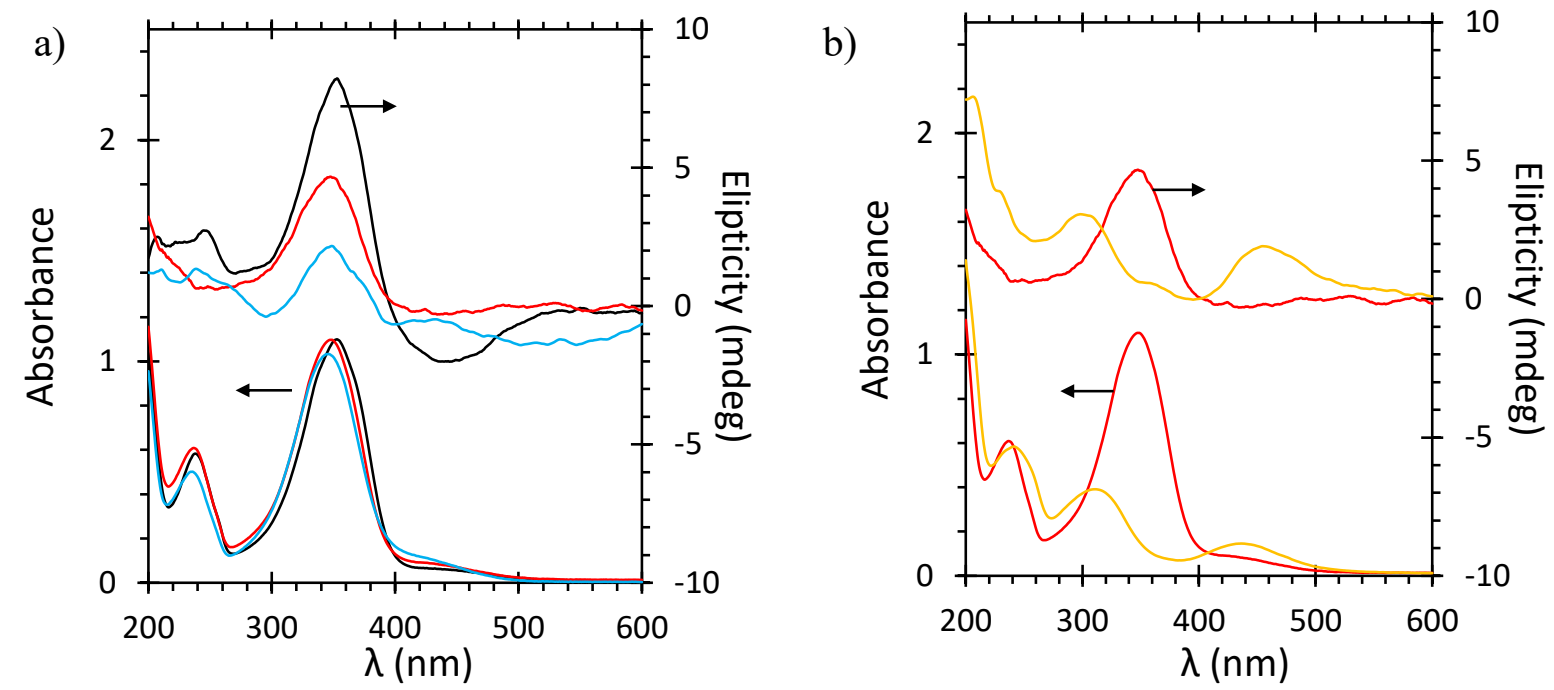

Figure 1. Circular dichroism (up) and UV-Vis (down) spectra of a) AZOt@ @CD (black), AZOt@ $\beta C D$ (red) and AZOt@ $@ \gamma C D$ (blue) inclusion complexes and b) AZOt@ $\beta C D$ (red) and $\mathrm{AZO} c @ \beta C D$ (orange) inclusion complexes.

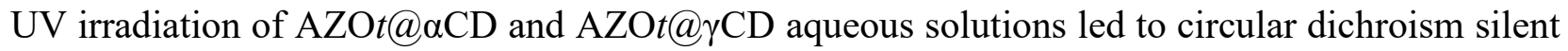
samples (Figure S2). Photoisomerization of AZOt chromophores changes the molecular geometry from a rod-like and non-polar trans isomer to a bended and polar cis isomer. The resulting silent circular dichroism spectra proved that the cis isomer cannot be hosted in $\alpha$ - or $\gamma \mathrm{CD}$ cavity.

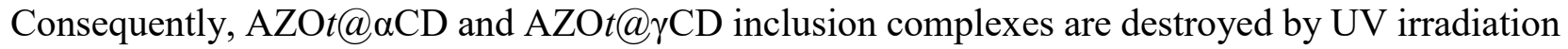
and $\mathrm{CD}-\mathrm{AZO} c$ chirality transfer cannot occur. On the contrary, AZOc@ $\beta \mathrm{CD}$ after UV irradiation retained a chiral signal (Figure 1b) centered on $\pi-\pi^{*}$ and $n-\pi^{*}$ absorption bands of AZOc. These 
results suggest the formation of a new inclusion complex between $\mathrm{AZO} c$ chromophore and $\beta \mathrm{CD}$. $\mathrm{AZO} c @ \beta C D$ interactions have already been described ${ }^{10,19}$ and are attributed to an equatorial complex between cis-azobenzene derivatives and $\beta \mathrm{CD}^{20}$. In summary, $\mathrm{AZO} t$ forms inclusion complexes with all three cyclodextrins, whereas $\mathrm{AZO} c$ only interacts with $\beta \mathrm{CD}$.

\section{Stoichiometry}

Both circular dichroism and UV-visible spectrophotometry showed a signal to noise ratio incompatible with a precise determination of the stoichiometry of the inclusion complexes. For this reason, the determination of each complex stoichiometry was performed by Job plots known as the continuous variation method, using ${ }^{1} \mathrm{H} \mathrm{NMR}^{21}$. Figure 2 shows the Job plots obtained for the four complexes previously detected, and the corresponding spectra are reported in Figures S3-S6.
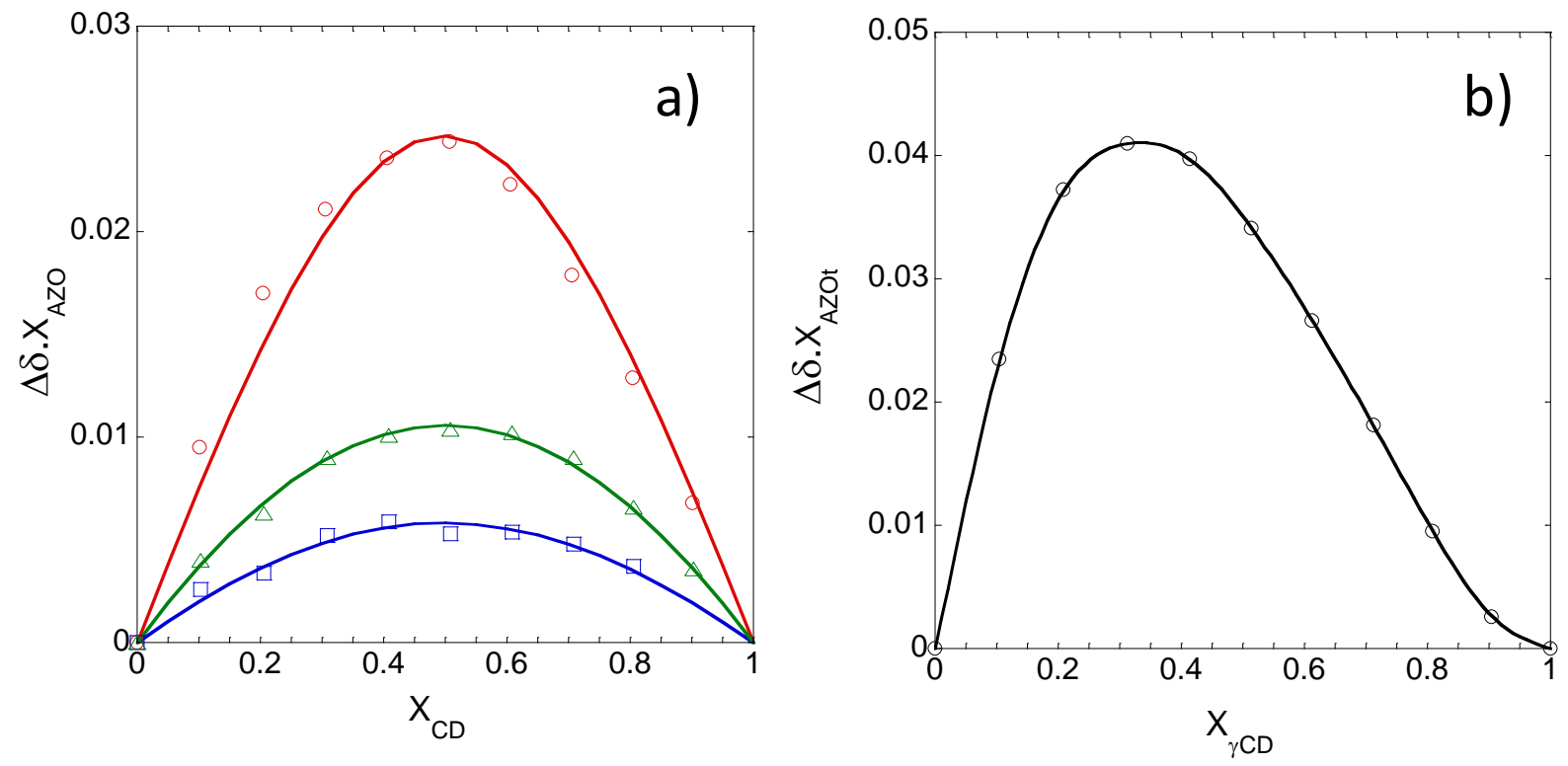

Figure 2. Job plot of the different complexes a) AZO $t$ in the presence of $\alpha$ (red $\circ$ ) and $\beta C D$ (blue $\square)$ and $\mathrm{AZO} c$ in the presence of $\beta \mathrm{CD}($ green $\Delta$ ). b) $\mathrm{AZO} t$ in the presence of $\gamma \mathrm{CD}$

Maxima were found at $\mathrm{R}=0.5$, which suggests a $1: 1$ stoichiometry of the AZOt@ $\alpha \mathrm{CD}$, AZOt@ $\beta C D$ and AZOc@ $\beta C D$ host-guest inclusion complexes (Figure 2a). In a recent study, 
Ulatowski et al. ${ }^{1 \mathrm{c}}$ have drawn the attention to the fact that such symmetrical NMR plots could not completely rule out the presence of a slight amount of 2:1 complex in the mixture. They showed by simulations that neglecting the presence of this second complex could lead to an underestimation of the 1:1 association constant. By increasing in a logarithmic manner the concentration of the Job plot experiment, they showed that increasing the proportion of 2:1 complex shifts the maximum of the Job plot toward $\mathrm{X}_{\mathrm{CD}}=0.33$. So finally, the plot reflects the proportion of each complex in agreement with the fact that dilution favors dissociation. In our case, we cannot completely rule out the possibility of the presence of a slight amount of 2:1 complex just on the observation of the Job plot. However, the subsequent study to determine the 1:1 association constant using UV-visible spectrophotometry will help answering this point. Indeed, in the hypothesis that both complexes 1:1 and 2:1 form, the relative concentrations of AZO (lower than for NMR) and CD (reaching a much larger excess) used for the UV-visible technique would shift the system even further in favor of the 1:1 complex. Furthermore, as we will see in the following section, isosbestic points ${ }^{22}$ observed in the UV-visible spectra evolution also point to a simple binary mixture. The concentration of a 2:1 complex, if any, would be negligible and the recorded data representative of the 1:1 complexation allowing a reliable determination of the corresponding association constant. These observations are moreover consistent with the various examples in the literature showing 1:1 complexes as the most favored system for $\alpha-$ and $\beta C D^{2 a, 12}$.

The Job plot for $\mathrm{AZO} t$ in presence of $\gamma \mathrm{CD}$ is different with a maximum at $\mathrm{X}_{\gamma \mathrm{CD}}=0.33$, pointing to a clear 2:1 stoichiometry (Figure $2 b$ ). The possibility that $\gamma \mathrm{CD}$ could complex two guest molecules has already been reported in the literature, linked to its large cavity ${ }^{23}$. The shape of the Job plot shows another particularity which is the inflection point when $\mathrm{X}_{\gamma \mathrm{CD}}$ tends to 1 . Ulatowski et al. related a similar case suggesting a sign of a 2:1 complex where the 1:1 complex does not impact the 
chemical shift of the signal followed ${ }^{1 \mathrm{c}}$. This result could also suggest a very small 1:1 association constant compared to the $2: 1$ one. This would lead in this part of the plot to a negligible amount of complex formed. This interpretation of two very different constants is again comforted by the isosbestic points observed on the UV-visible spectra evolution pointing at a binary mixture of free AZO and 2:1 inclusion complex.

The data provided by the photoisomerization reaction do not allow a direct quantitative determination of all the parameters involved in such complex model. It was then essential to decompose the experimental systems into subsystems that could be analyzed independently. For instance, the kinetics of formation of the inclusion complexes which is much faster than the photoisomerization process, deserves independent experiments and related modelling.

\section{Association constant and UV-visible spectra of the complexes}

Association constants $\left(\mathrm{K}_{\mathrm{a}}\right)$ were determined by fitting the UV-visible spectrophotometry data obtained at constant concentration of AZO with increasing CD concentration. The changes in absorbance of $\mathrm{AZO} t$ and $\mathrm{AZO} c$ were recorded against the concentration of $\mathrm{CD}$ up to a large excess of $\mathrm{CD}$ at $23^{\circ} \mathrm{C}$ (Figure 3). The possibility to use a much larger excess of $\mathrm{CD}$ than for a Job plot gives rise to significant variations on UV-vis spectra upon complexation and a better signal-to-noise ratio compared to the previous Job Plot experiments. Our main motivation was however the possibility to get the association constant and the spectra of the related complexes, both needed in the following for modeling the experiments under irradiation. 

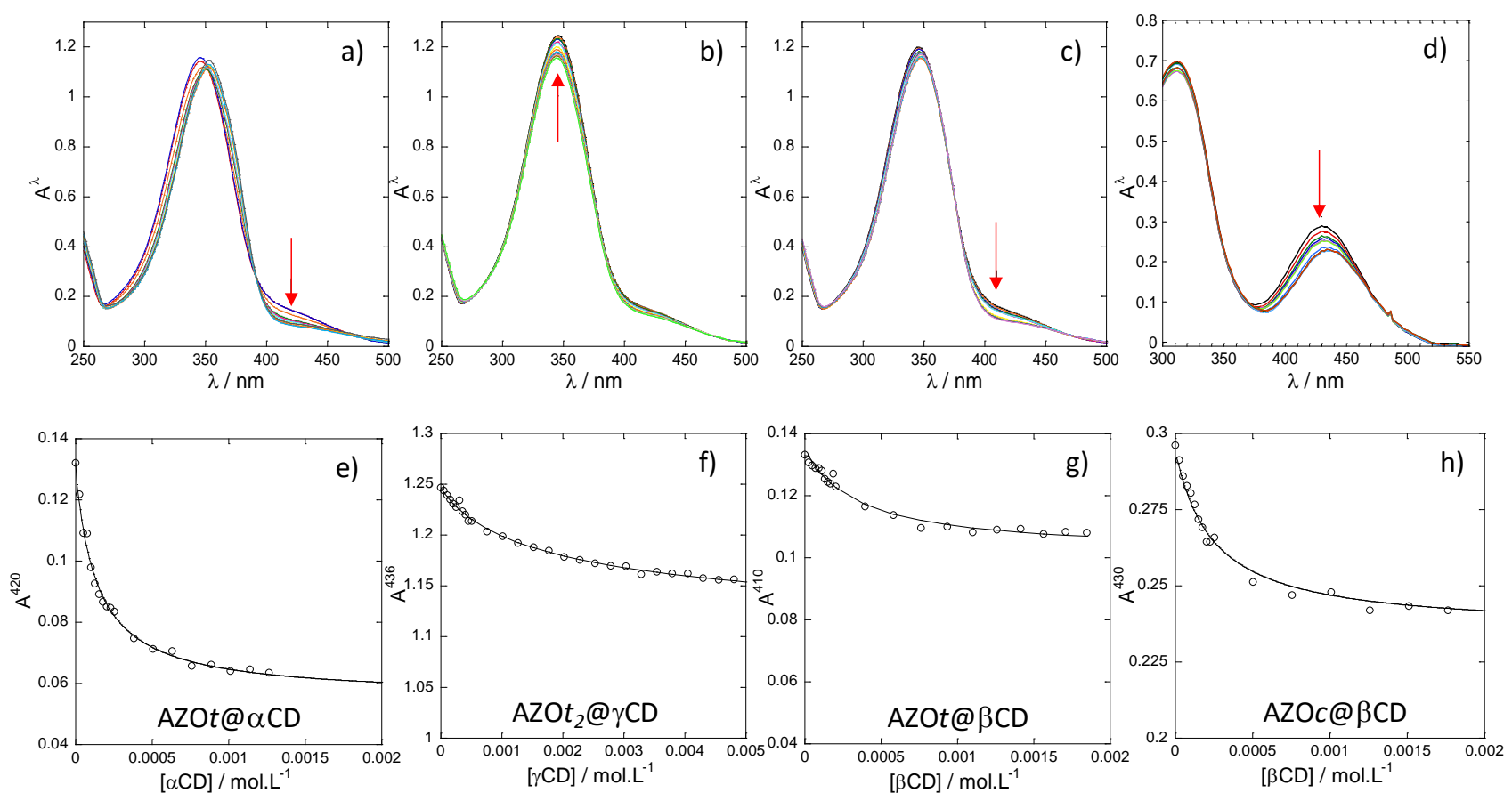

Figure 3. Spectra evolution of a) $[\mathrm{AZO} t]_{0}=5.5 \times 10^{-5}$ mol. $\mathrm{L}^{-1}$ with increasing $\alpha \mathrm{CD}$; b) $[\mathrm{AZO} t]_{0}=$ $5.3 \times 10^{-5}$ mol. $\mathrm{L}^{-1}$ with $\gamma \mathrm{CD}$ and c) $[\mathrm{AZO} t]_{0}=5.2 \times 10^{-5} \mathrm{~mol} \cdot \mathrm{L}^{-1}$ with $\beta \mathrm{CD}$ and d) for $[\mathrm{AZO} c]_{0}=$ $1.04 \times 10^{-5}$ mol. $\mathrm{L}^{-1}$ with $\beta C D$. Evolution of e) $\mathrm{A}^{420}$ versus $[\alpha \mathrm{CD}]$ for $\mathrm{AZO} t$; f) $\mathrm{A}^{436}$ versus $[\gamma \mathrm{CD}]$ for $\mathrm{AZO} t ; \mathrm{g}) \mathrm{A}^{410}$ versus $[\beta \mathrm{CD}]$ for $\left.\mathrm{AZO} t ; \mathrm{h}\right) \mathrm{A}^{430}$ versus $[\beta C D]$ for $\mathrm{AZO} c$.

Open circles: experimental points; continuous line: simulation.

The variations on UV-visible spectra upon the addition of CD are different for all the tested inclusion complexes. For $\alpha \mathrm{CD}$, as already mentioned, the $\lambda_{\max }$ shifts from 346 to $354 \mathrm{~nm}$. Three isosbestic points are observed at 348,392 and $460 \mathrm{~nm}$. These isosbestic points account for the exchange between two species only, free AZO $t$ and $\alpha \mathrm{CD}$ complex. For $\gamma \mathrm{CD}, \lambda_{\max }$ slightly shifts from 346 to $345 \mathrm{~nm}$ and two isosbestic points appear at 284 and $470 \mathrm{~nm}$. As already mentioned, the observation of isosbestic points in these 2.1 stoichiometry indicates that, in the concentration range explored, the amount of 1:1 complex that is transiently formed is undetectable.

In the case of $\beta \mathrm{CD}$ and $\mathrm{AZO} t$ isomer inclusion complex, $\lambda_{\max }$ shifts to $347 \mathrm{~nm}$ and a unique isosbestic point is observed at $480 \mathrm{~nm}$. For the inclusion complex with the $\mathrm{AZO} c$ isomer, the $\lambda_{\max }$ of the UV-Vis absorption spectrum of $\mathrm{AZO} c$ was shifted from $330 \mathrm{~nm}$ to $337 \mathrm{~nm}$ upon addition of 
$\beta C D$, and no isosbestic point is observed. For each AZO@CD complex, the wavelength showing the highest amplitude was chosen for absorbance versus CD concentration data fitting. For the fitting procedure to converge to a unique solution, the model must strictly reflect the information available in the experimental data. For AZOt, a 1:1 complexation is the only process at play for $\alpha \mathrm{CD}$ and $\beta \mathrm{CD}$, and a direct 2:1 complexation was considered for $\gamma \mathrm{CD}$. The association constant provided by the fitting procedure is hence the product of the $1: 1$ and $2: 1$ association constant. For the cis isomer, the initial solution of $\mathrm{AZO} c$ was prepared by irradiation at $366 \mathrm{~nm}$ until the photostationary state was reached. This solution contained 5\% of the trans isomer (as evidenced by ${ }^{1} \mathrm{H} N M R$ ), and this was taken into account to calculate the spectrum of the $\mathrm{AZO} c$ free isomer (Figure S7). Complexation of the residual $\mathrm{AZO} t$ was included in the model using the previously determined equilibrium constant for AZO $t @ \beta C D$. The small amount of $\mathrm{AZO} t$ did not really make an impact on the value of the association constant but it influenced the calculated spectrum of the complex. Finally, for each fitting procedure, two parameters needed to be determined: the association constant $\mathrm{K}_{\mathrm{a}}$ and the molar absorption coefficient of the inclusion complex $\varepsilon_{\text {AzO@CD }}$ at the chosen wavelength. The process considered and the wavelength chosen in each case are gathered together with the results obtained for the equilibrium constant and the molar absorption coefficient in Table 1. The standard deviations given for $\mathrm{K}_{\mathrm{a}}$ and $\varepsilon_{\mathrm{AzO} . \mathrm{CD}}$ are obtained from the variability observed for the treatment of at least three experiments.

\begin{tabular}{|c|c|c|c|c|}
\hline \multicolumn{2}{|c|}{ Processes } & $\lambda / \mathrm{nm}$ & $\mathrm{K}_{\mathrm{a}} / \mathrm{L}_{\mathrm{mol}}{ }^{-1}$ & $\varepsilon_{\mathrm{AZOCD}} / \mathrm{L} \cdot \mathrm{mol}^{-1} \cdot \mathrm{cm}^{-1}$ \\
\hline $\mathrm{AZO} t+\alpha \mathrm{CD} \rightleftarrows$ & AZOt@aCD & 420 & $7000 \pm 350$ & $1160 \pm 100$ \\
\hline $\mathrm{AZO} t+\beta \mathrm{CD} \rightleftarrows$ & AZOt@ $\beta C D$ & 410 & $3000 \pm 150$ & $2370 \pm 200$ \\
\hline $\mathrm{AZO} c+\beta \mathrm{CD} \rightleftarrows$ & AZOc@ßCD & 430 & $4000 \pm 900$ & $2200 \pm 200$ \\
\hline $2 \mathrm{AZO} t+\gamma \mathrm{CD} \rightleftarrows$ & $\mathrm{AZOt_{2 } @ \alpha C D}$ & 346 & $400000 \pm 20000^{a}$ & $35900 \pm 3000$ \\
\hline
\end{tabular}


Table 1. Calculated association constants $\mathrm{K}_{\mathrm{a}}$ of $\mathrm{AZO} @ \mathrm{CD}$ inclusion complexes and molar absorption coefficient

${ }^{\mathrm{a}}$ in $\left(\mathrm{L} \cdot \mathrm{mol}^{-1}\right)^{2}$

The titration data were in agreement with circular dichroism observations.AZOt@aCD was indeed more stable than AZOt@ $\beta C D$. For the comparison with AZOt $t_{2} @ \gamma \mathrm{CD}(2: 1$ inclusion complex), the simulation showed that for a given $\mathrm{AZO} t$ concentration and a twofold excess of CD, the free $\mathrm{AZO} t$ remaining at equilibrium was about the half for $\gamma \mathrm{CD}$ while less than $5 \%$ was left for the 1:1 complexes with either $\alpha$ - or $\beta C D$.

The determined equilibrium constants of the inclusion complexes formed by both trans and cis AZO with $\beta C D$ were similar. The $\mathrm{K}_{\mathrm{a}}$ of AZOt@ $\beta \mathrm{CD}$ found in this work is higher than most of the values reported in the literature. For instance in the case of $p$-methyl red, $\mathrm{K}_{\mathrm{a}}$ was found equal to 43 at $\mathrm{pH}$ $1^{24}$ and 1300 L.mol $^{-1}$ in basic conditions ${ }^{10}$. However, it should be noted that the association constant is very dependent on the azobenzene substitution, either through electronic or steric effects. Regarding AZOc@ $\beta \mathrm{CD}$, complexes in aqueous solutions usually present a higher $\mathrm{K}_{\mathrm{a}}$ compared to AZOt@ $\beta C D$ ones, ranging from 300 L.mol $^{-1}$ for azobenzene-grafted hyaluronanic acid to 4000 L.mol ${ }^{-1}$ for $p$-methyl red $^{7 b, 10}$. From a global standpoint, taking into account the accuracy of the determined values, no strong difference is observed in the affinity constants of trans and cis isomers for $\beta C D^{7 b}, 10,13,17$, which is consistent with our results. It should be mentioned here that the complexation of cis azobenzene derivatives is often disregarded in the preparation of advanced materials, based on the generally accepted idea that the trans isomer exhibits a higher affinity for $\beta C D$ than the cis isomer ${ }^{25}$. However, our experiments prove that this assertion is not valid in 
aqueous systems. Based on the application of such complexes linked to biology, many examples of the literature could be biased owing to the existence of cis azobenzene@ $\beta C D$ complexes.

With the association constants at hand, we were then able to calculate the UV-Vis spectra of the complexes (Figure $\mathrm{S} 8$ ). For all $\mathrm{AZO} t$ systems involving only two compounds, the spectra were obtained using the expression $\varepsilon_{\text {complex }}=\left(\mathrm{A}^{\lambda}-\left(\mathrm{A}^{\lambda}{ }_{0} \times\left([\mathrm{AZO} t] /[\mathrm{AZO} t]_{0}\right)\right)\right) /[$ complex $] \times 1$ with $\mathrm{A}_{0}{ }_{0}$ is the initial absorbance of free AZO and 1 is the optical path $(1 \mathrm{~cm})$. In the case of $\mathrm{AZO} c$, the absorption coefficient was obtained thanks to $\varepsilon_{\mathrm{AZO} c . \beta \mathrm{CD}}=\left(\mathrm{A}^{\lambda}-\varepsilon_{\mathrm{AZO} t} \times 1 \times[\mathrm{AZO} t]-\varepsilon_{\mathrm{AZOt} . \mathrm{BCD}} \times 1\right.$ $\left.\times[\mathrm{AZO} t @ \beta \mathrm{CD}]-\varepsilon_{\mathrm{AZO} c} \times 1 \times[\mathrm{AZO} c]\right) / 1 \times[\mathrm{AZO} c @ \beta \mathrm{CD}]$, taking into account the contribution of the residual $\mathrm{AZO} t(5 \%)$ in the initial solution.

The properties of the calculated spectra coincided with the description given above. When observed, the isosbestic points were at their expected position. Because of its 2:1 stoichiometry, the calculated spectrum of AZO $t_{2} @ \gamma \mathrm{CD}$ was about twice the intensity of the AZO $t @ \alpha-$ or $\beta \mathrm{CD}$ complexes. The position of the isosbestic points was thus obtained by dividing the spectrum of the complex by a factor 2. Therefore, in this case the isosbestic point accounts for the equality of $\varepsilon / 2$. At the end of this part, the association constants between AZO and all CDs were known as well as the molar absorption coefficients of the inclusion complexes at all wavelengths.

\section{II- Photokinetic study of AZO}

The next step was thus to analyze the behavior of all complexes when submitted to irradiation. We followed the photochemical reaction using UV-visible spectrophotometry under continuous 
irradiation (see experimental part). For the step by step construction of the model, we first considered the photochemistry of the pure AZO compound.

\section{AZO photoisomerization}

We successively used two irradiation wavelengths (366 or $420 \mathrm{~nm}$ ), to promote respectively transto-cis or cis-to-trans azobenzene isomerization. To acquire sufficient data to feed the model, for each $\mathrm{AZO} / \mathrm{CD}$ mixture, three experiments were performed in a row. The final photostationary state obtained for one run was the starting point of the following one.

Under $366 \mathrm{~nm}$ irradiation the initial $\mathrm{AZO} t\left(\pi-\pi^{*}\right)$ absorption band centered at $346 \mathrm{~nm}$ steadily decreases, giving rise to a new absorption band of lower intensity with a maximum at $430 \mathrm{~nm}$. This corresponded to $\mathrm{AZO} c \mathrm{n}-\pi^{*}$ band, and the isosbestic point that appears at $417 \mathrm{~nm}$ accounted for a simple trans-cis photoisomerization (Figure 4).

At the photostationary state, $\mathrm{AZO}_{C}$ was the major compound in solution $(95 \%$, value determined by ${ }^{1} \mathrm{H}$ NMR). The irradiation was then switched to $420 \mathrm{~nm}$ bringing the system back to AZO $t$. However at the end of this run, the initial absorbance, observed before irradiation at $366 \mathrm{~nm}$, is not recovered at the photostationary state. This implies that the solution at this resulting photostationary state is a mixture of the two isomers. For the third photoreaction the irradiation wavelength was switched back to $366 \mathrm{~nm}$, the initial solution being a mixture of trans and cis AZO isomers, it thus constituted a good test to validate the model. 

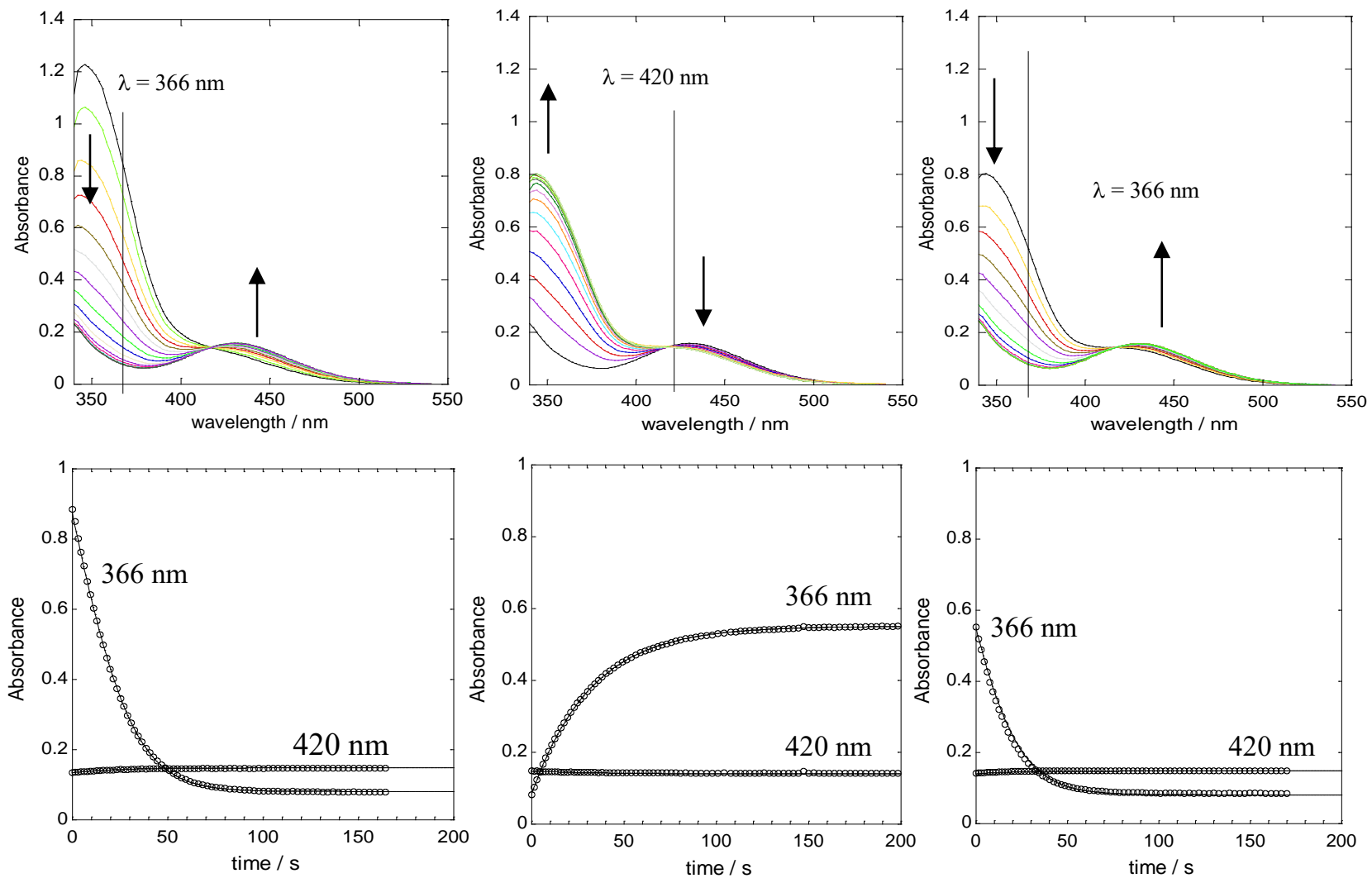

Figure 4. up: Spectral evolution of the AZOt - AZOc isomerization under irradiation at $366 \mathrm{~nm}$ (left), $420 \mathrm{~nm}$ (middle), and $366 \mathrm{~nm}$ (right). [AZO $t]_{0}=5.45 \times 10^{-5}$ mol.L ${ }^{-1}$; The arrows indicate the sense of evolution of the spectrum, the vertical lines indicate the irradiation wavelengths. down: Absorbance at 366 and $420 \mathrm{~nm}$ for three successive runs starting from $\mathrm{AZO}_{\mathrm{t}}$ and irradiated at: $\lambda=$ $366 \mathrm{~nm}$ (left), $\lambda=420 \mathrm{~nm}$ (middle), $\lambda=366 \mathrm{~nm}$ (right). Dots: experiment; continuous line: simulation.

\section{The model}

Under irradiation, three processes had to be considered: direct and reverse photoisomerization and a thermal $\mathrm{AZO} c$ to $\mathrm{AZO} t$ transformation (eq (1)).

$\mathrm{AZO} t \rightleftarrows \mathrm{AZO} c\left(\phi_{\mathrm{AZO} t}^{\lambda}, \phi_{\mathrm{AZO} o}^{\lambda}, \mathrm{k}-1\right)$

The determination of the thermal reverse processes can be easily reached by a first order treatment of the data obtained by switching off the $366 \mathrm{~nm}$ irradiation once the photostationary state had been 
reached. The spontaneous evolution from $\mathrm{AZO} c$ to $\mathrm{AZO} t$ was very slow leading to $\mathrm{k}_{-1}=7 \times 10^{-6} \mathrm{~s}^{-1}$ at $23^{\circ} \mathrm{C}$ (Figure S9). This value corresponds to a half-life of more than twenty-seven hours and its contribution is negligible when compared with the duration of the photochemical kinetics examined below (less than $15 \mathrm{~min}$ ). Nevertheless, this parameter was taken into account in the model and the value fixed in all following calculations.

The rate of the photochemical processes where $i$ represents $\mathrm{AZO} t$ or $\mathrm{AZO} c$ are given by: $\mathrm{r}_{\mathrm{i}}=-\phi_{i}^{\lambda} \varepsilon_{i}^{\lambda}[i] \mathrm{l}_{\mathrm{r}} \mathrm{I}_{0}^{\lambda} \mathrm{F}^{\lambda}$, where $\mathrm{F}^{\lambda}$ stands for the photokinetic factor, $\mathrm{F}^{\lambda}=\left(1-10^{-\mathrm{Abs}^{\lambda}}\right) / \mathrm{Abs}^{\lambda}$ with $\mathrm{Abs}^{\lambda}=\left(\varepsilon_{\mathrm{AZO}_{t}}^{\lambda} \cdot\left[\mathrm{AZO}_{t}\right]+\varepsilon_{\mathrm{AZO}_{C}}^{\lambda} \cdot\left[\mathrm{AZO}_{c}\right]\right) 1_{\mathrm{r}} \cdot \phi_{i}^{\lambda}$ stands for the quantum yield of the photochemical reaction of $i$ at the irradiation wavelength $\lambda$ (366 or $420 \mathrm{~nm}$ ), $\mathrm{I}_{0}^{\lambda}$ is the monochromatic irradiation photon flux at $\lambda, \varepsilon_{i}^{\lambda}$ is the molar extinction coefficient of compound $i$ at $\lambda ; 1_{\mathrm{r}}$ is the photochemical reactor irradiation optical path and $\mathrm{Abs}^{\lambda}$ is the absorbance of the solution at wavelength $\lambda$. The differential equation giving the evolution of the two isomers is: $\mathrm{r}=-\mathrm{d}\left[\mathrm{AZO}_{t}\right] / \mathrm{dt}=\mathrm{d}\left[\mathrm{AZO}_{C}\right] / \mathrm{dt}=\mathrm{r}_{\mathrm{AZO}}{ }^{-\mathrm{r}_{\mathrm{AZO} c}}-\mathrm{k}_{-1}\left[\mathrm{r}_{\mathrm{AZO}}\right]$

The aim was then to reproduce the experimental kinetic curves (figure 4, lower row) in order to retrieve missing parameters.

\section{Fitting procedure}

Several parameters were already at hand: $\mathrm{I}_{0}^{\lambda}$ was obtained by chemical actinometry (see experimental part), $1_{\mathrm{r}}(=1 \mathrm{~cm})$ was determined by the geometry of the system (see experimental part), $\varepsilon_{\mathrm{AZO}_{\mathrm{t}}}{ }^{\lambda}$ and $\varepsilon_{\mathrm{AZO}_{\mathrm{c}}}{ }^{\lambda}$ had been obtained in previous section according to UV-visible spectroscopy titration. Four parameters were left: the direct and reverse photochemical quantum yields at the two irradiation wavelengths. 
The three photochemical experiments described above $(366 \mathrm{~nm}-420 \mathrm{~nm}-366 \mathrm{~nm})$, each followed at the two irradiation wavelengths, were presented to the model. These two wavelengths (366 nm and $420 \mathrm{~nm}$ ) were chosen to follow the dynamic of the reaction because their corresponding absorbance determined the evolution of the photokinetic factor $\mathrm{F}^{\lambda}$. The evolution at $366 \mathrm{~nm}$ showed high amplitude for all runs, more suitable for parameter extraction than $420 \mathrm{~nm}$ which was very close to the isosbestic point. At such point, the value of $\varepsilon_{\mathrm{AZO}}{ }^{420}$ could be easily reached but this value is independent of the underlying kinetics, being then of no help in extracting kinetics parameters. In any case, and because of the existence of an isosbestic point, all the wavelengths (except the isosbestic point itself) provided the same information. The initial slope at $366 \mathrm{~nm}$ provided the quantum yields of the direct processes ( $\phi_{\mathrm{AZO} t}$ at $366 \mathrm{~nm}$ and $\phi_{\mathrm{AZO} c}$ at $420 \mathrm{~nm}$ ) while the photostationary state provides the values for the reverse processes ( $\phi_{\mathrm{AZO} c}$ at $366 \mathrm{~nm}$ and $\phi_{\mathrm{AZO} t}$ at $420 \mathrm{~nm})$.

The procedure followed for parameter extraction was the same for all cases (free and complexed AZO below). To start the fitting process, only the first experiment was presented to the model, putting special attention to fit perfectly the initial absorbance to the experimental data in order to enable a correct reproduction of the initial slope. For this, the $\varepsilon$ of the initial major compound (AZO $t$ or complexed AZO $t$ ) was slightly refitted always within the error given in Table 2. This parameter was then fixed until the end of the procedure. The quantum yields at $366 \mathrm{~nm}$ were then adjusted. A very good fit was already obtained at this stage but to get a perfect starting point for the second experiment, the $\varepsilon$ of the product $(\mathrm{AZO} c$ or complexed $\mathrm{AZO} c$ ) was also allowed to vary (see errors in Table 2). The final calculated concentrations were then taken as the initial condition for the second experiment while the parameters just determined were fixed. The only unknown parameters were then the two quantum yields at $420 \mathrm{~nm}$, which were easily reached by the model. At that point, 
once the initial conditions of the third run were obtained, the model quantitatively reproduced the experimental curves, which validate the values of the extracted parameters. At this stage, the predicted simulated curves reproduced the experimental ones with a very high accuracy; all parameters were however refitted simultaneously on all curves in order to find the common minimum for the three experiments. The values delivered for the quantum yields varied for less than $1.5 \%$ and the absorption coefficients remained within the limits of the error declared in Table 2. The quantitative reproduction of the experimental data confirmed that this simple model is sufficient to account for the observed kinetics. The quantum yields for the transformation of $\mathrm{AZO} t$ were equal at both wavelengths, which is logical since the same absorption band is concerned. For AZOc, quantum yields are higher at the two wavelengths because of the two absorption bands involved. In top of reproducing the experimental curves, this model allowed for the quantification of the trans and $c$ is isomer during the photoreaction and in the photostationary state. While AZOc reached $95 \%$ after irradiation at $366 \mathrm{~nm}$, AZOt represented only $60 \%$ of the total mass at the end of the $420 \mathrm{~nm}$ irradiation while $40 \%$ remained as AZOc.

\section{III - Photokinetics of the AZO@CD complexes}

At this stage, we were able to analyze the photoreactivity of the AZO@CD inclusion complexes. The initial parameters calculated in the previous steps were: 1) the supramolecular complexation equilibrium for each $\mathrm{CD}$, considered to be faster than the photoisomerization kinetics; and 2) the photoreactivity of free AZO. We then added in each case the reactivity of the different AZO@CD inclusion complexes. We considered in all cases that isomerization was simultaneous to ejection of the AZO compound (see processes in Table 3). To account for the different properties of the supramolecular complexes AZO/CD, three individual models were constructed for $\alpha$ - $\beta$ - and $\gamma \mathrm{CD}$. 
The AZO@ $\alpha$ CD model was the simplest one, with the formation of a 1:1 complex and the reactivity of free and bound AZO. The parameters related to complexation and photoisomerization of free AZO were fixed, the two unknown parameters being the photoisomerization quantum yields of AZO@ $\alpha \mathrm{CD}$ at the two irradiation wavelengths. Only one parameter per run needed to be determined which was obtained thanks to the set of data.

$\beta C D$ is able to form complexes with both trans and cis isomers. For this reason, the two supramolecular equilibria, namely the photoreactivity of free AZO as well as that of both $\mathrm{AZO} t @ \beta C D$ and $\mathrm{AZO} c @ \beta C D$ were considered. In this case, as the two isomers showed affinity for $\beta C D$, we could have considered that the compound remained in the cavity after isomerization. However, the dynamics provided by the model and the extracted parameters were strictly identical whether we considered isomerization inside the CD cavity AZO $t @ \beta C D \overleftrightarrow{\longrightarrow}$ AZOc@ $\beta C D$ or

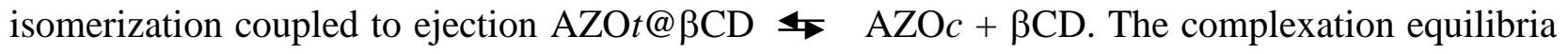
being fast ${ }^{26}$, they result in the same distribution of each species for both models.

Therefore, four quantum yields (for the two complexes at both wavelengths) could be determined for AZO@ $\beta C D$ using the presented step-by-step procedure.

Finally, the model for AZOt $t_{2} @ \gamma \mathrm{CD}$ included two encaged AZO $t$ inside $\gamma \mathrm{CD}$ cavity and we considered that isomerization and ejection occurred simultaneously. Again, the presence of isosbestic points during photoizomerization indicated that a hypothetical complex for which only one $\mathrm{AZO} t$ had switched to $\mathrm{AZO} c(\mathrm{AZO} c . \mathrm{AZO} t @ \gamma \mathrm{CD})$ was not detectable in our experiment and hence could not be taken into account in our modeling. Thus, as in the first case, only two quantum yields needed to be determined. 
The complete figures together with the fitted kinetics are qualitatively similar to figure 4 , they are all given in SI (Figures S10-S12). All the parameters obtained are gathered in Tables 2 and 3.

Table 2. molar absorption coefficients obtained for free and complexed AZOt and AZOc at the two irradiation wavelengths (366 and $420 \mathrm{~nm}$ ). The error indicates the variability observed on the absorption coefficients during the fitting procedure.

\begin{tabular}{|c|c|c|c|c|}
\hline & \multicolumn{2}{|c|}{$\mathrm{AZO} t$} & \multicolumn{2}{|c|}{$\mathrm{AZO} c$} \\
\hline & $\varepsilon(366)$ L. $\mathrm{mol}^{-1} \mathrm{~cm}^{-1}$ & $\varepsilon(420) \mathrm{L} \cdot \mathrm{mol}^{-1} \mathrm{~cm}^{-1}$ & $\varepsilon(366)$ L. $\mathrm{mol}^{-1} \mathrm{~cm}^{-1}$ & $\varepsilon(420) \mathrm{L} . \mathrm{mol}^{-1} \mathrm{~cm}^{-1}$ \\
\hline Free AZO & $16000 \pm 1000$ & $1710 \pm 100$ & $700 \pm 100$ & $2600 \pm 300$ \\
\hline$\alpha \mathrm{CD}-\mathrm{AZO}$ & $20000 \pm 1500$ & $1150 \pm 100$ & & \\
\hline$\gamma \mathrm{CD}-\mathrm{AZO}$ & $25000 \pm 1000$ & $3700 \pm 200$ & & \\
\hline$\beta C D-A Z O$ & $16500 \pm 2000$ & $1800 \pm 100$ & $1900 \pm 100$ & $3700 \pm 200$ \\
\hline
\end{tabular}

Table 3. Photochemical processes and quantum yields obtained at the two irradiation wavelengths. The error indicates the variability observed on the quantum yields during the fitting procedure.

\begin{tabular}{|l|l|l|l|l|}
\hline & $\phi_{\mathrm{AZO} t}(366)$ & $\phi_{\mathrm{AZO} t}(420)$ & $\phi_{\mathrm{AZO} c}(366)$ & $\phi_{\mathrm{AZO} c}(420)$ \\
\hline $\mathrm{AZO} t \gtrless \mathrm{AZO} c$ & $0.35 \pm 0.01$ & $0.35 \pm 0.01$ & $0.43 \pm 0.03$ & $0.50 \pm 0.03$ \\
\hline $\mathrm{AZO} t @ \alpha \mathrm{CD} \rightarrow \mathrm{AZO} c+\alpha \mathrm{CD}$ & $0.25 \pm 0.02$ & $0.26 \pm 0.02$ & & \\
\hline $\mathrm{AZO} t_{2} @ \gamma \mathrm{CD} \rightarrow 2 \mathrm{AZO} c+\gamma \mathrm{CD}$ & $0.10 \pm 0.01$ & $0.10 \pm 0.01$ & & \\
\hline $\mathrm{AZO} t @ \beta \mathrm{CD} \rightarrow \mathrm{AZO} c+\beta \mathrm{CD}$ & $0.29 \pm 0.02$ & $0.30 \pm 0.02$ & & \\
\hline $\mathrm{AZO} c @ \beta C D \rightarrow \mathrm{AZO} t+\beta \mathrm{CD}$ & & & $0.62 \pm 0.1$ & $0.42 \pm 0.05$ \\
& & & & \\
\hline
\end{tabular}

To the best of our knowledge, this is the first report on azobenzene photoisomerization quantum yield determination in water. The quantum yield of trans-cis photoisomerization increases with increasing solvent polarity, whereas the quantum yield of cis-trans photoisomerization is known to 
be independent of the polarity of the solvent ${ }^{27}$. Following this trend, the photoisomerization quantum yield of trans-cis isomerization of AZO in water is higher than the ones reported in the literature $^{28}$. The values reported in the literature are not directly comparable to our results as they were obtained in different solvents and irradiation wavelengths. However, in agreement with our results, trans-cis isomerization quantum yields are always lower than the ones for cis-trans transformation. For instance, the quantum yields at $439 \mathrm{~nm}$ for trans-cis and cis-trans were measured at 0.35 and 0.41 , respectively in a water/ethanol mixture. These results are in relatively good agreement with our results if we consider that both experimental conditions and the structure of the AZO compound were different. ${ }^{28 \mathrm{~b}}$

The quantum yields obtained for all AZOt complexes were always lower than the ones obtained for the free AZO. This trend was already observed in azobenzene @CD inclusion complexes in mixtures of water and ethanol and attributed to the apolar environment provided by the inner cavity of the $\mathrm{CD}^{23 \mathrm{~b}}$. The steric hindrance caused by the complexation inside $\mathrm{CD}$ compared to free $\mathrm{AZO} t$ might also contribute to this decrease of the determined quantum yield ${ }^{29}$. The quantum yield appears to be much lower for $\gamma \mathrm{CD}$ but in fact, taking into account its 2:1 stoichiometry, the quantum yield per $\mathrm{AZO} t$ molecule is 0.2 , only slightly lower than the other $\mathrm{AZO} t$ complexes. This further decrease might be explained by higher steric constrains compared to the other 1:1 AZOt@CD complexes caused by the inclusion of 2 molecules of AZO $t$ inside $\gamma \mathrm{CD}$ cavity.

The quantum yield for $\mathrm{AZO} c @ \beta \mathrm{CD}$ complex is higher than the free $\mathrm{AZO} c$. Such increase on the photoisomerization quantum yield on cis-trans isomerization with $\beta C D$ complexes was already observed by Bortulus and Monti, and attributed to a different geometry of AZOt@ $\beta \mathrm{CD}$ complex compared to $\mathrm{AZO} t @ \alpha \mathrm{CD}^{23 \mathrm{~b}}$. However, in this pioneer study the complex AZOc@@ $\beta \mathrm{CD}$ was not detected. The formation of an equatorial complex between $\mathrm{AZO} c$ and $\beta \mathrm{CD}$, as observed by circular 
dichroism, could provide a more polar, less sterically hindered environment compared to $\mathrm{AZO} t @ \beta C D$ axial complex and it is coherent with a higher quantum yield. Finally, the discrepancies observed in the quantum yield for $\mathrm{AZO} c @ \beta \mathrm{CD}$ at different excitation wavelengths (Table 2) are expected due the mixed nature of the cis-azobenzene excited states, in opposition to the non-mixed excited states of trans-azobenzene ${ }^{30}$.

\section{CONCLUSION}

We have presented a new step-by-step method for quantitatively determine the photoreactivity of inclusion complexes, including stoichiometry, affinity constant, UV-visible spectra of all the involved compounds, and quantum yields at two irradiation wavelengths. We have applied this method to study for the first time the photochemistry of different azobenzene-cyclodextrin inclusion complexes, widely used for preparing photoactive biomaterials, in water. Indeed, we found that the affinity constants in water of AZOt@ $\beta \mathrm{CD}$ and $\mathrm{AZO} c @ \beta \mathrm{CD}$ are similar, which can limit the potential applications of this supramolecular photoswitch. We hope that the insights in the photoreactivity of AZO@CD inclusion complexes provided in this work will be useful for the design of new bioactive materials. Beyond the precise study of AZO@CD inclusion complexes, the procedure presented here in detail could easily be applied to any photoreactive system. The procedure is secured since all the parameters are validated after each step.

\section{EXPERIMENTAL SECTION}

AZO was synthesized following an already published procedure ${ }^{7 \mathrm{a}}$, NMR spectra are given in Figure S13. Ultrapure water was obtained from an ELGA Purelab Flex system (resistivity higher than 18.2 MS.cm). Deuterated water and deuterated chloroform were purchased from Euriso-top (Cambridge). All experiments were performed at $23^{\circ} \mathrm{C}$. 
UV-Visible spectrometry. All the experiments have been implemented with a HP 8452A DiodeArray spectrometer at $23{ }^{\circ} \mathrm{C}$ using $10 \mathrm{~mm}$ large quartz cell. The data processing was made with Olis GlobalWorks software. Continuous irradiation of the sample was simultaneous to spectral recording and performed with two LED from Mightex: $365 \mathrm{~nm}$ (WLS-LED-0365-03) and $420 \mathrm{~nm}$ (WLSLED-0420-03). An optic fiber is used to carry the light from the LED to the side of the sample cell in a perpendicular geometry versus the measurement beam. The LEDs were used at their maximal power. A metallic grid with 4,4\% of transmittance is placed between the optic fiber and the sample. Before each experiment, an actinometry with ferrioxalate was performed to check the light intensity (I0) delivered by the LED to the sample ${ }^{31}$.

Circular dichroism. The circular dichroism was measured in a JASCO 815 using a scan speed of $200 \mathrm{~nm} \mathrm{~min}{ }^{-1}$ and averaging 3 full scans per spectra. AZO concentration of measured solution was adjusted to $5 \times 10^{-5} \mathrm{M} . \alpha-, \beta C D$ and $\gamma \mathrm{CD}$ concentration in the final solution was adjusted to $5 \times 10^{-3}$ $\mathrm{M}, 5 \times 10^{-3} \mathrm{M}$ and $5 \times 10^{-2} \mathrm{M}$, respectively, to assure complete formation of the corresponding supramolecular complexes.

Irradiation of free azobenzene. $0.1 \mathrm{mM}$ solution of free AZO was prepared and sonicated for 15 min. $1 \mathrm{~mL}$ of this solution was poured in a quartz cell and $1 \mathrm{~mL}$ of deionized water was added. A magnetic stirrer was added and the cell placed in the spectrometer under magnetic stirring. The content of the cell was successively irradiated at $365 \mathrm{~nm}, 420 \mathrm{~nm}$ and $365 \mathrm{~nm}$. The evolution of the absorbance of the mixture between $320 \mathrm{~nm}$ and $540 \mathrm{~nm}$ was recorded for each irradiation until the photostationary state was reached.

Irradiation of the complexes. $0.1 \mathrm{mM}$ solution of free AZO was prepared and sonicated for 15 min. Aqueous solutions of host $\alpha-, \beta$-, $\gamma$-cyclodextrins were prepared in concentration $3.6 \mathrm{mM}, 9.9$ 
$\mathrm{mM}$ and $18 \mathrm{mM}$ respectively and sonicated for $10 \mathrm{~min} .1 \mathrm{~mL}$ of guest solution and $1 \mathrm{~mL}$ of host solution were added in a quartz cell containing a magnetic stirrer. The content of the cell was successively irradiated at $365 \mathrm{~nm}, 420 \mathrm{~nm}$ and $365 \mathrm{~nm}$ under magnetic stirring. The evolution of the absorbance of the mixture between $320 \mathrm{~nm}$ and $540 \mathrm{~nm}$ was recorded for each irradiation until the photostationary state was reached.

Sample preparation for NMR. For the Job plots, ten solutions were prepared in NMR tubes with $\mathrm{X}_{\mathrm{H}}$ between 0 and 0.9 varying every 0.1 . The chemical shift observed was the two aromatic protons in ortho of PEG chain of the azobenzène. For each tube ${ }^{1} \mathrm{H}$ NMR spectrum was recorded with cryoprobe equipped $500 \mathrm{MHz}$ NMR spectrometer. The cryoprobe was necessary to calculate precisely the $\Delta \delta=\delta_{\text {obs }}-\delta_{\text {guest }}$ in very diluted mixture $\left(3.10^{-5}<[\mathrm{G}]<3.10^{-4}\right)$. Two $0.3 \mathrm{mM}$ solutions of AZO and cyclodextrin were prepared in $\mathrm{D}_{2} \mathrm{O}$ and sonicated for $10 \mathrm{~min}$. Ten NMR tubes were filled with these solutions so that each tube had a cyclodextrin ratio going from 0 to 1 every 0.1 and the total concentration of species $(\mathrm{AZO}+\mathrm{CD})$ always equals to $0.3 \mathrm{mM}$.

\section{Numerical modeling}

A homemade program SA was used to fit equilibrium and kinetic data ${ }^{32}$. The corresponding differential equations were integrated numerically using a semi-implicit Runge-Kutta method (see supporting information). In the first case, the corresponding kinetic equations are integrated until equilibrium is reached for each point. The values obtained at equilibrium for a set of parameters are then compared to the experimental data. In all cases, the unknown parameters were fitted automatically using an iterative algorithm of the Powell type, designed to minimize the residual quadratic error $E=\Sigma j \Sigma i[c i j-\mathrm{e} i j] 2 /(n \cdot N)$ where $c i j$ and $e i j$ are the computed and experimental 
values of concentrations respectively, $n$ is the number of data point in a given run, and $N$ is the number of runs.

\section{ASSOCIATED CONTENT}

Supporting Information. Detailed simulation process, Inactive CD spectra, kinetics of isomerization of the complexes, NMR spectra.

\section{AUTHOR INFORMATION}

\section{Corresponding Author}

* pimienta@chimie.ups-tlse.fr, afmingo@chimie.ups-tlse.fr

\section{Present Addresses}

† PASTEUR, Département de Chimie, École Normale Supérieure, PSL University, Sorbonne Université, CNRS UMR 8640, 24 rue Lhomond, 75005 Paris France.

\section{Author Contributions}

The manuscript was written through contributions of all authors. All authors have given approval to the final version of the manuscript.

\section{ACKNOWLEDGMENT}

The authors acknowledge the Toulouse IDEX structure and French National Research Agency (ANR GELLIGHT 18-CE06-0027-01) for their funding. Lab2Screen is acknowledged for the TOC design. 


\section{REFERENCES}

1. (a) Bruneau, E.; Lavabre, D.; Levy, G.; Micheau, J. C., Quantitative analysis of continuousvariation plots with a comparison of several methods: Spectrophotometric study of organic and inorganic 1:1 stoichiometry complexes. J. Chem. Education 1992, 69 (10), 833; (b) Thordarson, P., Determining association constants from titration experiments in supramolecular chemistry. Chem. Soc. Rev. 2011, 40 (3), 1305-1323; (c) Ulatowski, F.; Dąbrowa, K.; Bałakier, T.; Jurczak, J., Recognizing the Limited Applicability of Job Plots in Studying Host-Guest Interactions in Supramolecular Chemistry. J. Org. Chem. 2016, 81 (5), 1746-1756; (d) Brynn Hibbert, D.; Thordarson, P., The death of the Job plot, transparency, open science and online tools, uncertainty estimation methods and other developments in supramolecular chemistry data analysis. Chem. Comm. 2016, 52 (87), 12792-12805.

2. (a) Mura, P., Analytical techniques for characterization of cyclodextrin complexes in aqueous solution: A review. J. Pharm. Biomed. Anal. 2014, 101, 238-250; (b) Tan, S.; Ladewig, K.; Fu, Q.; Blencowe, A.; Qiao, G. G., Cyclodextrin-Based Supramolecular Assemblies and Hydrogels: Recent Advances and Future Perspectives. Macromol. Rapid Comm. 2014, 35 (13), 1166-1184; (c) Harada, A.; Takashima, Y.; Nakahata, M., Supramolecular Polymeric Materials via CyclodextrinGuest Interactions. Acc. Chem. Res. 2014, 47 (7), 2128-2140; (d) Martinez, A.; Ortiz Mellet, C.; Garcia Fernandez, J. M., Cyclodextrin-based multivalent glycodisplays: covalent and supramolecular conjugates to assess carbohydrate-protein interactions. Chem. Soc. Rev. 2013, 42 (11), 4746-4773.

3. Yuen, F.; Tam, K. C., Cyclodextrin-assisted assembly of stimuli-responsive polymers in aqueous media. Soft Matter 2010, 6, 4613-4630.

4. Arslan, M.; Sanyal, R.; Sanyal, A., Cyclodextrin embedded covalently crosslinked networks: synthesis and applications of hydrogels with nano-containers. Polym. Chem. 2020, 11 (3), 615-629.

5. Tamesue, S.; Takashima, Y.; Yamaguchi, H.; Shinkai, S.; Harada, A., Photoswitchable Supramolecular Hydrogels Formed by Cyclodextrins and Azobenzene Polymers. Angew. Chem. Int. Edn 2010, 49 (41), 7461-7464.

6. Takashima, Y.; Hatanaka, S.; Otsubo, M.; Nakahata, M.; Kakuta, T.; Hashidzume, A.; Yamaguchi, H.; Harada, A., Expansion-contraction of photoresponsive artificial muscle regulated by host-guest interactions. Nature comm. 2012, 3, 1270-1278.

7. (a) Royes Mir, J.; Coudret, C.; Roux, C.; Benoit-Marquié, F.; Cazalès, M.; Séverac, C.; Lorenzo, C.; Mingotaud, A.-F., Rational Hydrogel Formulation Leads to Reversible and Enhanced Photocontrolled Rigidity. ChemPhotoChem 2017, 1 (7), 311-316; (b) Rosales, A. M.; Rodell, C. B.; Chen, M. H.; Morrow, M. G.; Anseth, K. S.; Burdick, J. A., Reversible Control of Network Properties in Azobenzene-Containing Hyaluronic Acid-Based Hydrogels. Bioconj. Chem. 2018, 29 (4), 905-913.

8. Lee, I. E. T.; Hashidzume, A.; Harada, A., A Light-Controlled Release System Based on Molecular Recognition of Cyclodextrins. Macromol. Rapid Comm. 2015, 36, 2055-2059.

9. Bortolus, P.; Monti, S., Cis-trans Photoisomerization of azobenzene-cyclodextrin inclusion complexes. J. Phys. Chem. 1987, 91, 5046-5050.

10. Sanchez, A. M.; de Rossi, R. H., Effect of $\beta$-Cyclodextrin on the Thermal Cis-Trans Isomerization of Azobenzenes. J. Org. Chem. 1996, 61, 3446-3451. 
11. Liu, Y.; Zhao, Y.-L.; Zhang, H.-Y.; Fan, Z.; Wen, G.-D.; Ding, F., Spectrophotometric Study of Inclusion Complexation of Aliphatic Alcohols by $\beta$-Cyclodextrins with Azobenzene Tether. J. Phys. Chem. B 2004, 108 (26), 8836-8843.

12. Huang, H.; Juan, A.; Katsonis, N.; Huskens, J., Competitive inclusion of molecular photoswitches in host cavities. Tetrahedron 2017, 73 (33), 4913-4917.

13. Wang, D.; Wagner, M.; Butt, H.-J.; Wu, S., Supramolecular hydrogels constructed by redlight-responsive host-guest interactions for photo-controlled protein release in deep tissue. Soft Matter 2015, 11 (38), 7656-7662.

14. Nehls, E. M.; Rosales, A. M.; Anseth, K. S., Enhanced user-control of small molecule drug release from a poly(ethylene glycol) hydrogel via azobenzene/cyclodextrin complex tethers. $J$. Mat. Chem. B 2016, 4 (6), 1035-1039.

15. Barao, C. E.; Pinheiro, K. H.; Valarini Junior, O.; Zanin, G. M.; Faria de Morae, F., Determination of the Association Constant of Alpha and Beta Cyclodextrins Using Methyl Orange. Ind. Biotech. 2016, 12 (5), 317-322.

16. Wang, Y.; Ma, N.; Wang, Z.; Zhang, X., Photocontrolled Reversible Supramolecular Assemblies of an Azobenzene-Containing Surfactant with $\alpha$-Cyclodextrin. Angew. Chem. Int. Edn 2007, 46, 2823-2826.

17. Zhang, L.; Zhang, H.; Gao, F.; Peng, H.; Ruan, Y.; Xu, Y.; Weng, W., Host-guest interaction between fluoro-substituted azobenzene derivative and cyclodextrins. RSC Advances 2015, 5 (16), 12007-12014.

18. Osawa, K.; Tagaya, H.; Kondo, S.-i., Induced Circular Dichroism of Achiral Cyclic Bisurea via Hydrogen Bonds with Chiral Carboxylates. J. Org. Chem. 2019, 84 (11), 6623-6630.

19. (a) Lee, W.-S.; Ueno, A., Photocontrol of the Catalytic Activity of a $\beta$-Cyclodextrin Bearing Azobenzene and Histidine Moieties as a Pendant Group. Macromol. Rapid Comm. 2001, 22 (6), 448-450; (b) Kim, J.-H.; Koo, E.; Ju, S.-Y.; Jang, W.-D., Multimodal Stimuli-Responsive Poly(2isopropyl-2-oxazoline) with Dual Molecular Logic Gate Operations. Macromolecules 2015, 48 (14), 4951-4956.

20. Barbiric, D. J.; Castro, E. A.; de Rossi, R. H., A molecular mechanics study of 1:1 complexes between azobenzene derivatives and $\beta$-cyclodextrin. J. Molec. Struct.: THEOCHEM 2000, 532 (1), 171-181.

21. (a) Fielding, L., Determination of Association Constants (Ka) from Solution NMR Data. Tetrahedron 2000, 56 (34), 6151-6170; (b) Bakirci, H.; Zhang, X.; Nau, W. M., Induced Circular Dichroism and Structural Assignment of the Cyclodextrin Inclusion Complexes of Bicyclic Azoalkanes. J. Org. Chem. 2005, 70 (1), 39-46.

22. Zhou, J.; Zou, S.-F.; Liang, W.-A., Spectrophotometric determination of equilibrium constants of two mutual competitive reactions by the method of isosbestic points. Talanta 1993, 40 (6), 925-929.

23. (a) Ueno, A.; Takahashi, K.; Hino, Y.; Osa, T., Fluorescence enhancement of $\alpha$ naphthyloxyacetic acid in the cavity of $\gamma$-cyclodextrin, assisted by a space-regulating molecule. $J$. Chem. Soc., Chem. Comm. 1981, (4), 194-195; (b) Bortolus, P.; Monti, S., cis trans Photoisomerization of azobenzene-cyclodextrin inclusion complexes. J. Phys. Chem. 1987, 91 (19), 5046-5050.

24. Kuwabara, T.; Aoyagi, T.; Takamura, M.; Matsushita, A.; Nakamura, A.; Ueno, A., Heterodimerization of Dye-Modified Cyclodextrins with Native Cyclodextrins. J. Org. Chem. 2002, 67 (3), 720-725. 
25. (a) Wang, D.; Zhao, W.; Wei, Q.; Zhao, C.; Zheng, Y., Photoswitchable Azobenzene/Cyclodextrin Host-Guest Complexes: From UV- to Visible/Near-IR-LightResponsive Systems. ChemPhotoChem 2018, 2 (5), 403-415; (b) Harada, A.; Takashima, Y., Macromolecular Recognition and Macroscopic Interactions by Cyclodextrins. Chem. Record 2013, 13 (5), 420-431.

26. Schönbeck, C., Complexation Kinetics of Cyclodextrins with Bile Salt Anions: Energy Barriers for the Threading of Ionic Groups. J. Phys. Chem. B 2019, 123, 9831-9838.

27. Bandara, H. M. D.; Burdette, S. C., Photoisomerization in different classes of azobenzene. Chem. Soc. Rev. 2012, 41 (5), 1809-1825.

28. (a) Ladányi, V.; Dvořák, P.; Al Anshori, J.; Vetráková, L.; Wirz, J.; Heger, D., Azobenzene photoisomerization quantum yields in methanol redetermined. Photochem. Photobiol. Sci. 2017, 16 (12), 1757-1761; (b) Bortolus, P.; Monti, S., Cis-trans photoisomerization of azobenzene. Solvent and triplet donors effects. J. Phys. Chem. 1979, 83 (6), 648-652.

29. Sierocki, P.; Maas, H.; Dragut, P.; Richardt, G.; Vögtle, F.; De Cola, L.; Brouwer, F.; Zink, J. I., Photoisomerization of Azobenzene Derivatives in Nanostructured Silica. J. Phys. Chem. B 2006, 110 (48), 24390-24398.

30. Satzger, H.; Root, C.; Braun, M., Excited-State Dynamics of trans- and cis-Azobenzene after UV Excitation in the $\pi \pi^{*}$ Band. J. Phys. Chem. A 2004, 108 (30), 6265-6271.

31. Amabilino, S.; Tasse, M.; Lacroix, P. G.; Mallet-Ladeira, S.; Pimienta, V.; Ak1, J.; Sasaki, I.; Malfant, I., Photorelease of nitric oxide (NO) on ruthenium nitrosyl complexes with phenyl substituted terpyridines. New J. of Chem. 2017, 41, 7371-7383.

32. Pimienta, V.; Lavabre, D.; Micheau, J. C., software available at this address http://cinet.chim.pagesperso-orange.fr/tele sa/install Sa Eng.html, together with examples and notice. Interested people are welcome to contact V. Pimienta for further help if needed. 